\title{
PENERAPAN SISTEM PENDUKUNG KEPUTUSAN DENGAN ANALISIS GAP UNTUK PEMILIHAN MAHASISWA BERPRESTASI TINGKAT FAKULTAS (PADA FAKULTAS TEKNOLOGI INFORMASI UNISKA)
}

\author{
Desy Ika Puspitasari, S.Kom., M.Kom. \\ (smile4desyka@gmail.com) \\ Al Fath Riza Kholdani, S.Kom., M.Kom. \\ (kholdanialfath@gmail.com)
}

\begin{abstract}
ABSTRAK
Kegiatan pemilihan mahasiswa berprestasi yang dilakukan oleh pihak fakultas seringkali menemukan permasalahan, karena dihadapkan pada banyaknya mahasiswa yang berprestasi. Pihak fakultas harus mengambil keputusan yang tepat, sehingga jika dilakukan dengan baik dan benar, maka akan menjamin hasil pemilihan yang akurat, dan dapat dipertanggungjawabkan. Subyek penelitian ini yaitu aplikasi pemilihan mahasiswa berpestasi dengan menerapkan gap analysis sebagai metode dalam pengambilan keputusan guna memberikan solusi permasalahan penentuan pemberian beasiswa mahasiswa berprestasi.

Analisis Gap merupakan suatu metode pengukuran untuk mengetahui kesenjangan (gap) antara kinerja suatu variabel dengan harapan konsumen terhadap variabel tersebut. Semakin kecil perbedaan (disebut juga gap) yang dihasilkan, maka bobot nilainya semakin besar yang berarti memiliki peluang lebih besar untuk mahasiswa dikategorikan sebagai mahasiswa berprestasi.

Informasi yang akan dihasilkan dari aplikasi ini yaitu penentuan calon mahasiswa berprestasi yang layak dan tidak layak diberikan beasiswa PPA secara cepat, tepat dan akurat dengan menerapkan metode analisis gap/profile matching. Terdapat perbedaan antara hasil pretest dengan hasil posttest, dimana hasil pretest terdapat 7 data yang akurat dan 2 data yang tidak akurat dengan persentase akurat sebesar 77,78\%. Sedangkan hasil posttest terdapat 8 data yang akurat dan 1 data yang tidak akurat dengan persentase akurat sebesar $88,89 \%$.
\end{abstract}

Kata Kunci : Analisis Gap/profile matching, pemilihan mahasiswa berprestasi.

\section{PENDAHULUAN}

Setiap tahunnya Fakultas Teknologi Informasi dihadapkan pada permasalahan dalam menentukan mahasiswa berprestasi, bagaimana agar di dalam proses pemilihan mahasiswa berprestasi lebih efektif dan efisien. Selain itu karena sistem yang belum terkomputerisasi juga merupakan masalah tersendiri dalam penentuan keputusan.

Sistem penunjang keputusan (SPK) dibutuhkan dalam mendukung pemilihan mahasiswa berprestasi tersebut, untuk Jurnal Ilmiah Fakultas Teknik "Technologia" menentukan keputusan yang diambil agar lebih tepat sasaran. SPK merupakan bagian dari Sistem Informasi berbasis komputer, termasuk sistem berbasis pengetahuan (manajemen pengetahuan) yang digunakan guna mendukung pengambilan keputusan (Asfi \& Sari, 2010).

Gap analysis merupakan suatu metode pengukuran untuk mengetahui kesenjangan (gap) antara kinerja suatu variabel dengan harapan konsumen terhadap variabel tersebut. Semakin kecil 
gapnya semakin baik. Biasanya perusahaan dengan tingkat pelayanan yang baik, akan mempunyai gap yang semakin kecil (Supriyana, 2010). Dalam penelitian ini, semakin kecil perbedaan (disebut juga gap) yang dihasilkan, maka bobot nilainya semakin besar yang berarti memiliki peluang lebih besar untuk mahasiswa dikategorikan sebagai mahasiswa berprestasi. Perangkingan yang dihasilkan dapat digunakan untuk membantu pihak fakultas dalam pengambilan keputusan pemilihan mahasiswa berprestasi agar tepat sasaran dan dapat dipertanggung jawabkan.

\section{METODE PENELITIAN}

Metode Pengumpulan Data

Adapun data hasil wawancara kepada bagian kemahasiswaan Fakultas Teknologi Informasi Uniska MAB Banjarmasin antara lain sebagai berikut :

Tabel 1. Tabel Bobot Kriteria

\begin{tabular}{|c|c|}
\hline Nama Kriteria & Nilai \\
\hline Status orang tua & 2 \\
\hline
\end{tabular}

\begin{tabular}{|l|l|}
\hline IPK & 3 \\
\hline Penghasilan orang tua & 3 \\
\hline Jumlah tanggungan & 3 \\
\hline Pernah terima beasiswa & 2 \\
\hline Karya ilmiah & 3 \\
\hline Kegiatan ekstrakulikuler & 2 \\
\hline Bahasa asing & 2 \\
\hline Kepribadian & 3 \\
\hline
\end{tabular}

Tabel 2. Pengelompokkan Core Factor

\begin{tabular}{|l|c|}
\hline \multicolumn{1}{|c|}{ Kriteria } & Jenis \\
\hline IPK & CF \\
\hline Penghasilan orang tua & CF \\
\hline Jumlah tanggungan & CF \\
\hline Karya ilmiah & CF \\
\hline Kegiatan ektrakulikuler & CF \\
\hline Bahasa Asing & $\mathrm{CF}$ \\
\hline
\end{tabular}

Tabel 3. Pengelompokkan Secondary Factor

\begin{tabular}{|l|c|}
\hline \multicolumn{1}{|c|}{ Kriteria } & Jenis \\
\hline Status orang tua & SF \\
\hline Pernah terima beasiswa & SF \\
\hline Kepribadian & SF \\
\hline
\end{tabular}

\section{Metode Pengolahan Data}

Tabel 4. Data 9 Mahasiswa Penerima Beasiswa PPA Pada Tahun Ajaran 2014/2015

\begin{tabular}{|c|c|c|c|c|c|c|c|c|c|c|c|}
\hline No & Nama & $\mathrm{C}_{1}$ & $\mathrm{C}_{2}$ & $\mathrm{C}_{3}$ & $\mathrm{C}_{4}$ & $\mathrm{C}_{5}$ & $\mathrm{C}_{6}$ & $\mathrm{C}_{7}$ & $\mathrm{C}_{8}$ & $\mathrm{C}_{9}$ & $\begin{array}{c}\text { Ketera } \\
\text { ngan }\end{array}$ \\
\hline 1. & $\begin{array}{l}\text { Tyas } \\
\text { Adinugroho }\end{array}$ & Lengkap & 3,67 & 4.003 .892 & 2 & Belum & 70 & 1 & Inggris & Sopan & Layak \\
\hline 2. & $\begin{array}{l}\text { Afiana Puji } \\
\text { Lestari }\end{array}$ & Lengkap & 3,71 & 1.486 .600 & 4 & Belum & 70 & 2 & $\begin{array}{l}\text { Inggris, } \\
\text { Jepang }\end{array}$ & Sopan & Layak \\
\hline 3. & Siti Mardiana & Lengkap & 3,50 & 1.000 .000 & 7 & Belum & 80 & 1 & Inggris & Sopan & $\begin{array}{l}\text { Tidak } \\
\text { Layak }\end{array}$ \\
\hline 4. & M. Rahmadani & Meninggal & 3.74 & - & - & Belum & 80 & 1 & Inggris & Sopan & Layak \\
\hline 5. & Riza Maulana & Lengkap & 3.74 & 1.000 .000 & - & Belum & 80 & 1 & Inggris & Sopan & Layak \\
\hline 6. & $\begin{array}{l}\text { Muhammad } \\
\text { Rafiq }\end{array}$ & Lengkap & 3.30 & 2.223 .250 & - & Belum & 70 & 1 & Inggris & Sopan & Layak \\
\hline 7. & $\begin{array}{l}\text { Lutfi } \\
\text { Hermawan }\end{array}$ & Meninggal & 3.46 & - & 8 & Belum & 75 & 2 & Inggris & Sopan & $\begin{array}{l}\text { Tidak } \\
\text { Layak }\end{array}$ \\
\hline 8. & Ilham Saputra & Meninggal & 3.58 & - & 6 & Sudah & 70 & 3 & Inggris & Sopan & $\begin{array}{r}\text { Tidak } \\
\text { Layak }\end{array}$ \\
\hline 9. & Samudi & Lengkap & 3.58 & 750.000 & 6 & Sudah & 85 & 1 & Inggris & Sopan & Layak \\
\hline
\end{tabular}

Sumber : FTI Uniska MAB Banjarmasin

Keterangan :

$\mathrm{C}_{1}$ : Status orang tua

$\mathrm{C}_{2}:$ IPK

$\mathrm{C}_{3}$ : Penghasilan orang tua

\section{Perancangan Peneltian}

Perancangan sistem basis data menggunakan metode pendekatan
$\mathrm{C}_{7}$ : Jumlah kegiatan ekstrakulikuler

$\mathrm{C}_{8}$ : Kemampuan bahasa asing

$\mathrm{C}_{9}$ : Kepribadian
$\mathrm{C}_{5}$ : Pernah terima beasiswa

$\mathrm{C}_{6}$ : Nilai karya ilmiah

terstruktur. Metode ini lebih menekankan pada aliran data, yaitu Data Flow Diagram (DFD).

Jurnal Ilmiah Fakultas Teknik "Technologia" 


\section{Data Flow Diagram}

\section{Diagram Konteks}

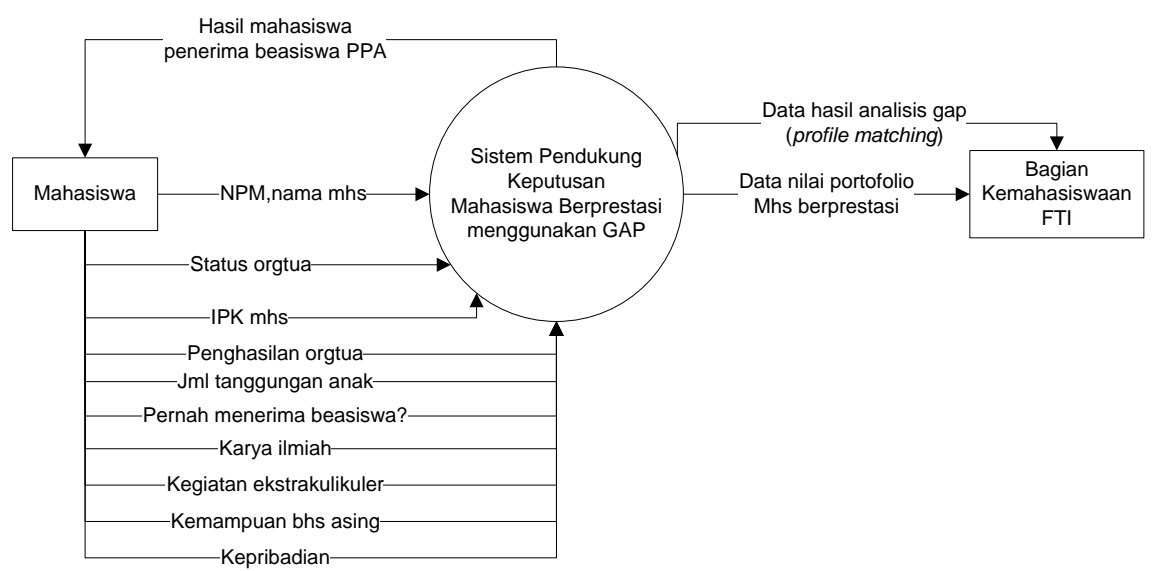

Gambar 1. Diagram Konteks SPK Mahasiswa Berprestasi Menggunakan GAP

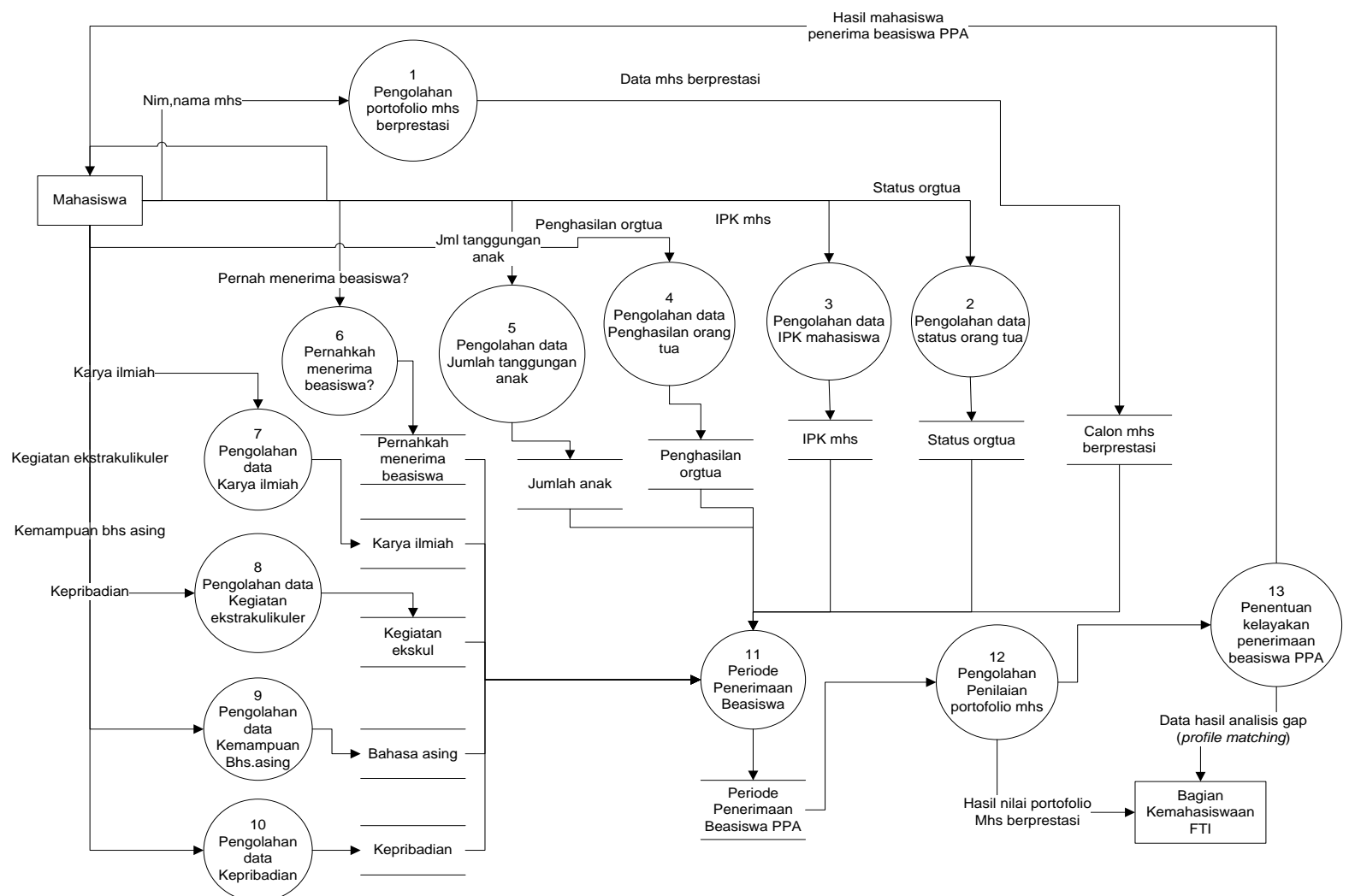

Gambar 2. DFD Level 0

Dari entitas mahasiswa dalam portofolio pengajuan beasiswa mahasiswa berprestasi, terdapat beberapa atribut yang dapat diolah dan diproses menjadi beberapa tabel. Proses 1 mengolah data portofolio mahasiswa berprestasi dan

disimpan dalam tabel calon mahasiswa berprestasi dengan NPM sebagai kode unik yang akan menjadi Jurnal Ilmiah Fakultas Teknik "Technologia" acuan beberapa proses berikutnya. Proses 2 mengolah status orang tua, apakah orang tua masih hidup atau telah meninggal, kemudian disimpan dalam tabel status orang tua. Proses 3 mengolah data IPK mahasiswa dan disimpan dalam tabel IPK, proses 4 mengolah data penghasilan orang tua, disimpan dalam tabel penghasilan orang tua, proses 5 mengolah data jumlah tanggungan anak, disimpan dalam tabel 
jumlah anak, proses 6 mengolah data status mahasiswa, apakah pernah menerima beasiswa atau belum pernah, disimpan dalam tabel pernahkah menerima beasiswa. Proses 7 mengolah data nilai karya ilmiah, disimpan dalam tabel karya ilmiah. Proses 8 mengolah data kegiatan ekstrakulikuler, banyak mahasiswa mengikuti kegiatan ekskul (disimpan dalam tabel kegiatan ekskul). Proses 9 mengolah data kemampuan bahasa asing (banyaknya kemampuan berbahasa asing), disimpan dalam tabel bahasa asing. Proses 10 pengolahan kepribadian mahasiswa, disimpan dalam tabel kepribadian. Beberapa proses tersebut merupakan syarat dari pengajuan beasiswa mahasiswa berprestasi.

\section{Desain Database}

\section{Relasi Antar Tabel}
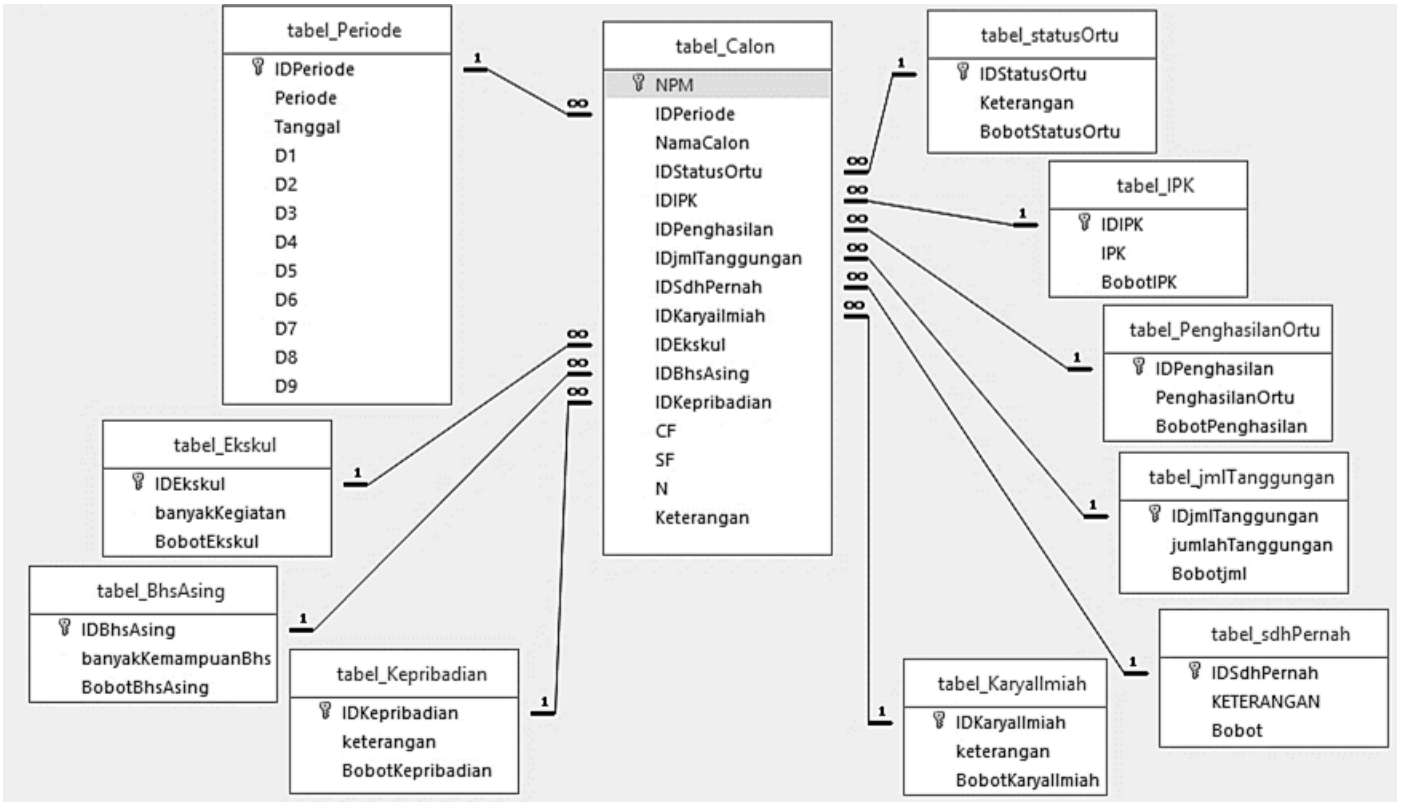

Gambar 3. Relasi Tabel

\section{Teknik Analisis Data}

\section{Analisa Metode Profile Matching}

Teknik analisa data dilakukan dengan menggunakan Profile Matching. Pertama adalah menghitung nilai gap untuk masing-masing kriteria. Dalam hal ini, proses perhitungan nilai gap dilakukan dengan menentukan selisih nilai antara profil calon penerima beasiswa dengan profil pencapaian yang merupakan acuan kelayakan penerimaan beasiswa PPA/bobot dari setiap kriteria yang telah ditentukan oleh Fakultas Teknologi Informasi UNISKA, atau dapat ditunjukkan pada rumus di bawah ini :

Gap $=$ Profil Mahasiswa-Profil Pencapaian maka didapatkan perhitungan nilai gap antara profil mahasiswa dengan profil pencapaian seperti berikut.

Tabel 5. Perhitungan Gap Calon Penerima Beasiswa

\begin{tabular}{|c|c|l|c|c|c|c|c|c|c|c|c|}
\hline No. & \multicolumn{1}{|c|}{ NIM } & \multicolumn{1}{|c|}{ NAMA } & C1 & C2 & C3 & C4 & C5 & C6 & C7 & C8 & C9 \\
\hline 1. & 12.63 .0050 & Tyas Adinugroho & 1 & 3 & 1 & 1 & 2 & 2 & 1 & 1 & 3 \\
\hline 2. & 13.63 .0497 & Afiana Puji Lestari & 1 & 3 & 2 & 2 & 2 & 2 & 2 & 2 & 3 \\
\hline 3. & 13.63 .0368 & Siti Mardiana & 1 & 2 & 2 & 3 & 2 & 3 & 1 & 1 & 3 \\
\hline 4. & 12.63 .0477 & M. Rahmadani & 2 & 3 & 3 & 1 & 2 & 3 & 1 & 1 & 3 \\
\hline 5. & 12.63 .0159 & Riza Maulana & 1 & 3 & 2 & 1 & 2 & 3 & 1 & 1 & 3 \\
\hline 6. & 12.63 .0318 & M. Rafiq & 1 & 1 & 2 & 1 & 2 & 2 & 1 & 1 & 3 \\
\hline
\end{tabular}




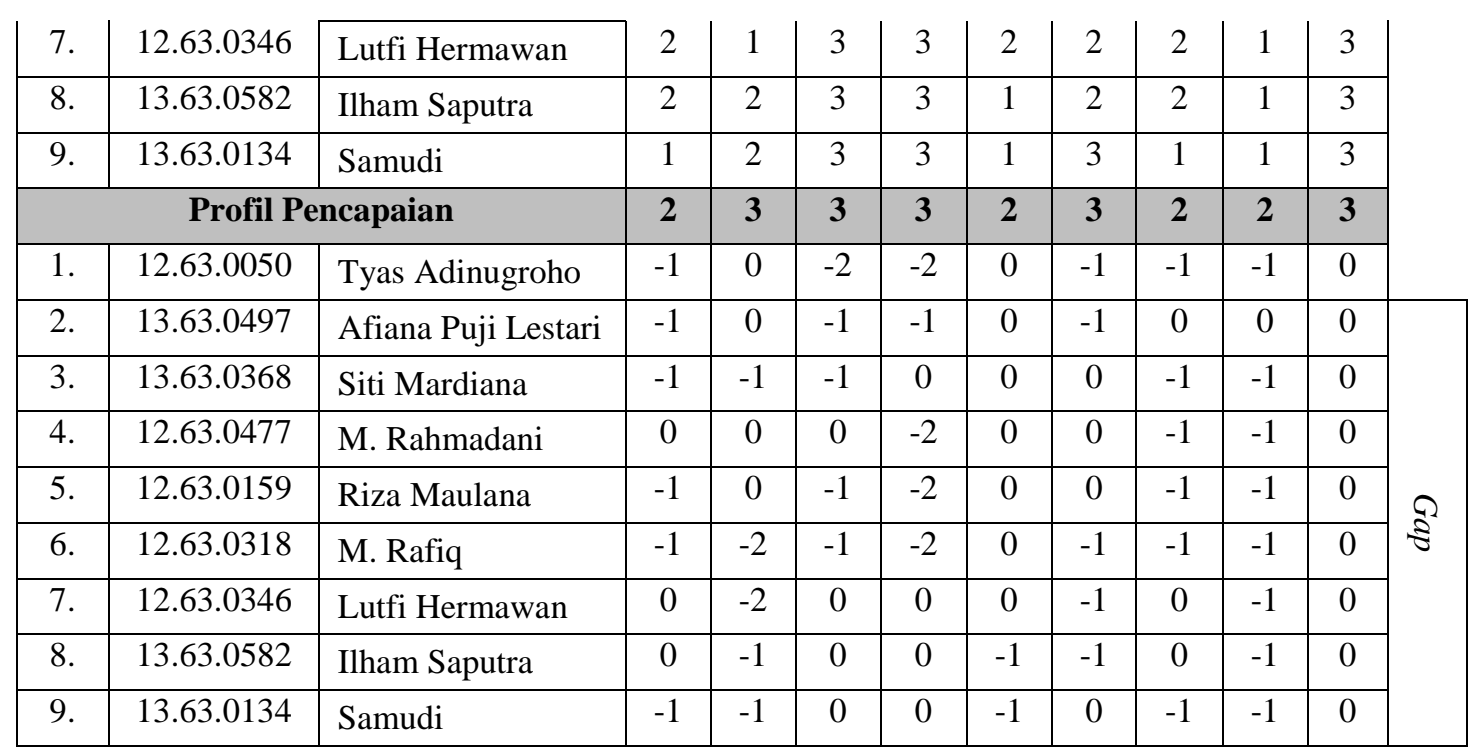

Langkah berikutnya adalah pembobotan. Setelah diperoleh gap dari masing-masing calon penerima beasiswa, maka setiap profil diberi bobot nilai dengan patokan tabel bobot nilai gap. Seperti bisa dilihat pada tabel di bawah ini.

Tabel 6. Bobot Nilai Gap

\begin{tabular}{|c|c|c|l|}
\hline No & $\begin{array}{c}\text { Selisih } \\
\text { Gap }\end{array}$ & Bobot Nilai & \multicolumn{1}{|c|}{ Keterangan } \\
\hline 1 & 0 & 6 & Kompetensi Sesuai Dengan Yang Dibutuhkan \\
\hline 2 & 1 & 5.5 & Kompetensi Individu Kelebihan Satu Tingkat \\
\hline 3 & -1 & 5 & Kompetensi Individu Kekurangan Satu Tingkat \\
\hline 4 & 2 & 4.5 & Kompetensi Individu Kelebihan Dua Tingkat \\
\hline 5 & -2 & 4 & Kompetensi Individu Kekurangan Dua Tingkat \\
\hline 6 & 3 & 3.5 & Kompetensi Individu Kelebihan Tiga Tingkat \\
\hline 7 & -3 & 3 & Kompetensi Individu Kekurangan Tiga Tingkat \\
\hline 8 & 4 & 2.5 & Kompetensi Individu Kelebihan Empat Tingkat \\
\hline 9 & -4 & 2 & Kompetensi Individu Kekurangan Empat Tingkat \\
\hline 10 & 5 & 1.5 & Kompetensi Individu Kelebihan Lima Tingkat \\
\hline 11 & -5 & 1 & Kompetensi Individu Kekurangan Lima Tingkat \\
\hline
\end{tabular}

Maka didapatkan hasil bobot nilai gap dari tiap calon penerima sebagai berikut :

Tabel 7. Hasil Bobot Nilai Gap Calon Penerima Beasiswa

\begin{tabular}{|c|c|c|c|c|c|c|c|c|c|c|c|}
\hline No. & NIM & NAMA & C1 & $\mathrm{C2}$ & C3 & $\mathrm{C4}$ & C5 & C6 & C7 & C8 & C9 \\
\hline 1. & 12.63 .0050 & Tyas Adinugroho & -1 & 0 & -2 & -2 & 0 & -1 & -1 & -1 & 0 \\
\hline 2. & 13.63 .0497 & Afiana Puji Lestari & -1 & 0 & -1 & -1 & 0 & -1 & 0 & 0 & 0 \\
\hline 3. & 13.63 .0368 & Siti Mardiana & -1 & -1 & -1 & 0 & 0 & 0 & -1 & -1 & 0 \\
\hline 4. & 12.63 .0477 & M. Rahmadani & 0 & 0 & 0 & -2 & 0 & 0 & -1 & -1 & 0 \\
\hline 5 . & 12.63 .0159 & Riza Maulana & -1 & 0 & -1 & -2 & 0 & 0 & -1 & -1 & 0 \\
\hline 6. & 12.63 .0318 & M. Rafiq & -1 & -2 & -1 & -2 & 0 & -1 & -1 & -1 & 0 \\
\hline 7. & 12.63 .0346 & Lutfi Hermawan & 0 & -2 & 0 & 0 & 0 & -1 & 0 & -1 & 0 \\
\hline 8. & 13.63 .0582 & Ilham Saputra & 0 & -1 & 0 & 0 & -1 & -1 & 0 & -1 & 0 \\
\hline 9. & 13.63 .0134 & Samudi & -1 & -1 & 0 & 0 & -1 & 0 & -1 & -1 & 0 \\
\hline
\end{tabular}

Jurnal Ilmiah Fakultas Teknik "Technologia" 


\begin{tabular}{|c|c|c|c|c|c|c|c|c|c|c|c|c|}
\hline \multicolumn{12}{|c|}{ Bobot Nilai GAP } & \\
\hline 1. & 12.63 .0050 & Tyas Adinugroho & 5 & 6 & 4 & 4 & 6 & 5 & 5 & 5 & 6 & \\
\hline 2. & 13.63 .0497 & Afiana Puji Lestari & 5 & 6 & 5 & 5 & 6 & 5 & 6 & 6 & 6 & \\
\hline 3. & 13.63 .0368 & Siti Mardiana & 5 & 5 & 5 & 6 & 6 & 6 & 5 & 5 & 6 & \\
\hline 4. & 12.63 .0477 & M. Rahmadani & 6 & 6 & 6 & 4 & 6 & 6 & 5 & 5 & 6 & \\
\hline 5. & 12.63 .0159 & Riza Maulana & 5 & 6 & 5 & 4 & 6 & 6 & 5 & 5 & 6 & \\
\hline 6. & 12.63 .0318 & M. Rafiq & 5 & 4 & 5 & 4 & 6 & 5 & 5 & 6 & 6 & \\
\hline 7. & 12.63 .0346 & Lutfi Hermawan & 6 & 4 & 6 & 6 & 6 & 5 & 6 & 5 & 6 & \\
\hline 8. & 13.63 .0582 & Ilham Saputra & 6 & 5 & 6 & 6 & 5 & 5 & 6 & 5 & 6 & \\
\hline 9. & 13.63 .0134 & Samudi & 5 & 5 & 6 & 6 & 5 & 6 & 5 & 5 & 6 & \\
\hline
\end{tabular}
secondary factor (faktor pendukung) para calon penerima beasiswa.

Berikut adalah rumus perhitungan nilai core factor dan secondary factor :

$$
N C F=\frac{\sum N C}{\sum I C} \quad N S F=\frac{\sum N S}{\sum I S}
$$

Keterangan :

$N C F=$ Nilai rata - rata core factor
Sehingga untuk lebih jelasnya hasil perhitungan nilai core factor dan secondary factor masing-masing calon pqugrima beasisswa dapat dilihat pada tabel di bawah inf. $I S$

Tabel 8. Perhitungan Core Factor dan Secondary Factor

\begin{tabular}{|c|l|c|c|c|c|c|c|c|c|c|c|c|}
\hline No. & $\begin{array}{c}\text { NAMA } \\
\text { MAHASISWA }\end{array}$ & C1 & C2 & C3 & C4 & C5 & C6 & C7 & C8 & C9 & CF & SF \\
\hline 1. & Tyas Adinugroho & 5 & 6 & 4 & 4 & 6 & 5 & 5 & 5 & 6 & 4,8 & 5,7 \\
\hline 2. & Afiana Puji Lestari & 5 & 6 & 5 & 5 & 6 & 5 & 6 & 6 & 6 & 5,5 & 5,7 \\
\hline 3. & Siti Mardiana & 5 & 5 & 5 & 6 & 6 & 6 & 5 & 5 & 6 & 5,3 & 5,7 \\
\hline 4. & M. Rahmadani & 6 & 6 & 6 & 4 & 6 & 6 & 5 & 5 & 6 & 5,3 & 6,0 \\
\hline 5. & Riza Maulana & 5 & 6 & 5 & 4 & 6 & 6 & 5 & 5 & 6 & 5,2 & 5,7 \\
\hline 6. & M. Rafiq & 5 & 4 & 5 & 4 & 6 & 5 & 5 & 6 & 6 & 4,8 & 5,7 \\
\hline 7. & Lutfi Hermawan & 6 & 4 & 6 & 6 & 6 & 5 & 6 & 5 & 6 & 5,3 & 6,0 \\
\hline 8. & Ilham Saputra & 6 & 5 & 6 & 6 & 5 & 5 & 6 & 5 & 6 & 5,5 & 5,7 \\
\hline 9. & Samudi & 5 & 5 & 6 & 6 & 5 & 6 & 5 & 5 & 6 & 5,5 & 5,3 \\
\hline
\end{tabular}

Langkah keempat metode profile matching ini adalah perhitungan nilai total berdasarkan persentase core factor dan secondary factor. Dimana persentase yang ditentukan oleh FTI UNISKA untuk core factor $70 \%$ dan secondary Factor $30 \%$.

Lebih jelasnya hasil perhitungan nilai total masing-masing calon penerima beasiswa dapat dilihat pada tabel di bawah ini :

Jurnal Ilmiah Fakultas Teknik "Technologia"
Rumus untuk perhitungan nilai total ini adalah sebagai berikut :

Keterangan :

$$
(x) \% N C F+(x) \% N S F=N
$$

NCF = Nilai rata - rata core factor

NSF = Nilai rata - rata secondary factor

$N=$ Nilai total dari aspek

$(x) \%=$ Nilai persen yang diinputkan

Tabel 9. Perhitungan Nilai Total Calon Penerima Beasiswa 


\begin{tabular}{|c|c|c|c|c|}
\hline No. & $\begin{array}{c}\text { NAMA } \\
\text { MAHASISWA }\end{array}$ & $\begin{array}{c}\text { Core } \\
\text { Factor }\end{array}$ & $\begin{array}{c}\text { Secondary } \\
\text { Factor }\end{array}$ & $\mathbf{N}$ \\
\hline 1. & Tyas Adinugroho & 4,8 & 5,7 & 5,08 \\
\hline 2. & Afiana Puji Lestari & 5,5 & 5,7 & 5,55 \\
\hline 3. & Siti Mardiana & 5,3 & 5,7 & 5,43 \\
\hline 4. & M. Rahmadani & 5,3 & 6,0 & 5,53 \\
\hline 5. & Riza Maulana & 5,2 & 5,7 & 5,32 \\
\hline 6. & M. Rafiq & 4,8 & 5,7 & 5,08 \\
\hline 7. & Lutfi Hermawan & 5,3 & 6,0 & 5,53 \\
\hline 8. & Ilham Saputra & 5,5 & 5,7 & 5,55 \\
\hline 9. & Samudi & 5,5 & 5,3 & 5,45 \\
\hline
\end{tabular}

Kemudian nilai dari setiap calon penerima beasiswa di urutkan dari yang terbesar sampai dengan yang terkecil selanjutnya melakukan penyeleksian apabila nilai calon penerima beasiswa $\geq$ 5.3 maka dinyatakan layak menerima beasiswa sedangkan apabila nilai calon penerima beasiswa $<5.3$ maka dinyatakan tidak layak menerima beasiswa.

Tabel 10. Rentang Nilai Kelayakan

\begin{tabular}{|c|c|}
\hline Rentang Nilai & Keterangan \\
\hline$\geq 5.3$ & Layak \\
\hline$<5.3$ & Tidak Layak \\
\hline
\end{tabular}

Berikut ini adalah hasil akhir proses profile matching :

Tabel 11. Hasil Akhir Proses Profile Matching

\begin{tabular}{|c|l|c|c|}
\hline No & Nama Mahasiswa & Score & Keterangan \\
\hline 1. & Tyas Adinugroho & 5,08 & Tidak layak \\
\hline 2. & Afiana Puji Lestari & 5,55 & Layak \\
\hline 3. & Siti Mardiana & 5,43 & Layak \\
\hline 4. & M. Rahmadani & 5,53 & Layak \\
\hline 5. & Riza Maulana & 5,32 & Layak \\
\hline 6. & Muhammad Rafiq & 5,08 & Tidak layak \\
\hline 7. & Lutfi Hermawan & 5,53 & Layak \\
\hline 8. & Ilham Saputra & 5,55 & Layak \\
\hline 9. & Samudi & 5,45 & Layak \\
\hline
\end{tabular}

Jurnal Ilmiah Fakultas Teknik "Technologia"
Maka didapatkan hasil calon penerima beasiswa yang layak diberikan beasiswa adalah Afiana Puji Lestari, Siti Mardiana, Muhammad Rahmadani, Riza Maulana, Lutfi Hermawan, Ilham Saputra dan Samudi. Sedangkan mahasiswa berprestasi yang tidak layak menerima beasiswa adalah Tyas Adi Nugroho dan Muhammad Rafiq.

\section{HASIL DAN PEMBAHASAN Hasil}

Form ini berfungsi menampilkan dan mencetak laporan data nilai portofolio dari data calon penerima beasiswa.

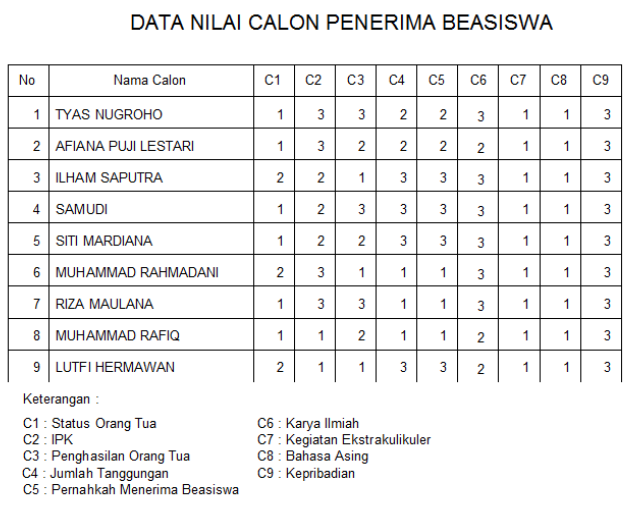

Gambar 1. Form Laporan Data Nilai

Form ini berfungsi menampilkan dan mencetak laporan dari data hasil profile matching.

DATA HASIL ANALISIS GAP (PROFILE MATCHING)

\begin{tabular}{|c|c|c|c|c|c|}
\hline No & Nama Calon & CF & $\mathrm{SF}$ & $\mathrm{N}$ & Keterangan \\
\hline 1 & ILHAM SAPUTRA & 5,5 & 5,7 & 5,2 & Layak \\
\hline 2 & SAMUDI & 5,5 & 5,3 & 5.45 & Layak \\
\hline 3 & TVAS NUGROHO & 4,8 & 5,7 & 5,08 & Tidak Layak \\
\hline 4 & AFIANA PUJI LESTARI & 5,5 & 5,7 & 5,55 & Layak \\
\hline 5 & STIMARDIANA & 5,3 & 5,7 & 5,43 & Layak \\
\hline 6 & MUHAMMAD RAHMADANI & 5,3 & 6 & 5,53 & Layak \\
\hline 7 & RIZA MAULANA & 5,2 & 5,7 & 5,32 & Layak \\
\hline 8 & MUHAMMAD RAFIQ & 4.8 & 5,7 & 5,08 & Tidak Layak \\
\hline 9 & LUTFI HERMAWAN & 5,3 & 6 & 5,53 & Layak \\
\hline
\end{tabular}

Gambar 2. Form Laporan Hasil Profile Matching

\section{Pembahasan \\ Pengujian sistem \\ Hasil Sebelum Implementasi}


Sebelum implementasi dilakukan, didapat data 9 calon mahasiswa yang mengajukan beasiswa PPA di FTI Uniska pada 2015, terdapat data 6 calon yang layak dan 3 calon yang tidak layak diberikan beasiswa. Sedangkan data seharusnya terdapat 7 calon yang layak dan 2 calon yang tidak layak.

Tabel 12. Pretest

\begin{tabular}{|c|c|l|c|c|}
\hline No & NPM & Nama & $\begin{array}{c}\text { Ketera } \\
\text { ngan }\end{array}$ & $\begin{array}{c}\text { Seharus } \\
\text { nya }\end{array}$ \\
\hline 1. & 12.63 .0050 & $\begin{array}{l}\text { Tyas } \\
\text { Adinugroho }\end{array}$ & Layak & Layak \\
\hline 2. & 13.63 .0497 & $\begin{array}{l}\text { Afiana Puji } \\
\text { Lestari }\end{array}$ & Layak & Layak \\
\hline 3. & 13.63 .0368 & $\begin{array}{l}\text { Siti } \\
\text { Mardiana }\end{array}$ & $\begin{array}{c}\text { Tidak } \\
\text { Layak }\end{array}$ & Layak \\
\hline 4. & 12.63 .0477 & $\begin{array}{l}\text { Muhammad } \\
\text { Rahmadani }\end{array}$ & Layak & Layak \\
\hline 5. & 12.63 .0159 & $\begin{array}{l}\text { Riza } \\
\text { Maulana }\end{array}$ & Layak & Layak \\
\hline 6. & 12.63 .0318 & $\begin{array}{l}\text { Muhammad } \\
\text { Rafiq }\end{array}$ & Layak & Tidak \\
Layak
\end{tabular}

\section{Hasil Sesudah Implementasi}

Sesudah implementasi dilakukan dengan menggunakan aplikasi yang menerapkan metode profile matching didapatkan data tentang hasil kelayakan penerimaan beasiswa PPA, dimana terdapat 7 calon yang layak dan 2 calon yang tidak layak diberikan beasiswa.

Berdasarkan penyajian data sebelum dan sesudah implementasi dengan menggunakan aplikasi yang menerapkan metode profile matching, terdapat perbedaan antara hasil pretest dengan hasil posttest, dimana hasil pretest terdapat 7 data yang akurat dan 2 data yang tidak akurat. Sedangkan hasil posttest terdapat 8 data yang akurat dan 1 data yang tidak akurat.

Tabel 13. Posttest

\begin{tabular}{|c|c|l|c|}
\hline No & NPM & \multicolumn{1}{|c|}{ Nama } & $\begin{array}{c}\text { Ketera } \\
\text { ngan }\end{array}$ \\
\hline 1. & 12.63 .0050 & Tyas Adinugroho & $\begin{array}{c}\text { Tidak } \\
\text { layak }\end{array}$ \\
\hline 2. & 13.63 .0497 & $\begin{array}{l}\text { Afiana Puji } \\
\text { Lestari }\end{array}$ & Layak \\
\hline 3. & 13.63 .0368 & Siti Mardiana & Layak \\
\hline 4. & 12.63 .0477 & $\begin{array}{l}\text { Muhammad } \\
\text { Rahmadani }\end{array}$ & Layak \\
\hline 5. & 12.63 .0159 & Riza Maulana & Layak \\
\hline 6. & 12.63 .0318 & Muhammad Rafiq & $\begin{array}{c}\text { Tidak } \\
\text { layak }\end{array}$ \\
\hline 7. & 12.63 .0346 & Lutfi Hermawan & Layak \\
\hline 8. & 13.63 .0582 & Ilham Saputra & Layak \\
\hline 9. & 13.63 .0134 & Samudi & Layak \\
\hline
\end{tabular}

\section{Hasil Perbandingan Pretest dan Posttest}

Dari hasil pretest dan posttest diperoleh data perbandingan sebagai berikut :

Tabel 14. Perbandingan Pretest dan Posttest

\begin{tabular}{|c|c|c|c|c|c|c|}
\hline \multirow{2}{*}{ No } & \multirow{2}{*}{ Nama } & \multicolumn{2}{|c|}{ Pretest } & \multirow{2}{*}{ Posttest } & \multicolumn{2}{c|}{ Keterangan } \\
\cline { 3 - 4 } \cline { 6 - 6 } & & Keterangan & Seharusnya & & Pretest & Posttest \\
\hline 1. & Tyas Adinugroho & Layak & Layak & Tidak layak & Akurat & Tidak Akurat \\
\hline 2. & Afiana Puji L. & Layak & Layak & Layak & Akurat & Akurat \\
\hline 3. & Siti Mardiana & Tidak Layak & Layak & Layak & Tidak Akurat & Akurat \\
\hline 4. & M. Rahmadani & Layak & Layak & Layak & Akurat & Akurat \\
\hline 5. & Riza Maulana & Layak & Layak & Layak & Akurat & Akurat \\
\hline 6. & M. Rafiq & Tidak Layak & Tidak Layak & Tidak layak & Akurat & Akurat \\
\hline 7. & Lutfi Hermawan & Layak & Layak & Layak & Akurat & Akurat \\
\hline 8. & Ilham Saputra & Tidak Layak & Layak & Layak & Tidak Akurat & Akurat \\
\hline 9. & Samudi & Layak & Layak & Layak & Akurat & Akurat \\
\hline
\end{tabular}

Setelah pengujian dilakukan dan diperoleh validitas pada pengujian tersebut melalui tabel yang disajikan di atas, maka

selanjutnya dapat digambarkan grafik perbandingan pretest dan posttest pada penggunaan aplikasi yang menerapkan metode profile matching, yaitu sebagai berikut :

Data akurat pretest $=$

$$
\frac{7}{9} \times 100 \%=77.78 \%
$$

Data akurat posttest $=$

$$
\frac{8}{9} \times 100 \%=88,89 \%
$$

Jurnal Ilmiah Fakultas Teknik "Technologia" 
Berdasarkan hasil perhitungan pretest dan posttest diatas, didapatkan nilai persentase posttest lebih besar dari pada persentase pretest.

\section{KESIMPULAN}

Setelah melewati proses analisis, desain dan implementasi program aplikasi, maka dapat ditarik kesimpulan :

1. Dapat membantu user dalam mengambil keputusan untuk menentukan calon mahasiswa berprestasi yang layak dan tidak layak diberikan beasiswa PPA secara cepat, tepat, dan akurat.

2. Berdasarkan penyajian data sebelum dan sesudah implementasi dengan menggunakan aplikasi yang menerapkan metode analisis gap/profile matching, terdapat perbedaan antara hasil pretest dengan hasil posttest, dimana hasil pretest terdapat 7 data yang akurat dan 2 data yang tidak akurat dengan persentase akurat sebesar $77,78 \%$. Sedangkan hasil posttest terdapat 8 data yang akurat dan 1 data yang tidak akurat dengan Saran persentase akurat sebesar $88,89 \%$.

Aplikasi ini masih memiliki banyak kekurangan, sehingga masih diperlukan pengembangan. Sangat diharapkan nantinya aplikasi ini dapat dikembangkan lagi dengan menggunakan metode-metode yang lain untuk menghasilkan hasil yang lebih baik.

\section{DAFTAR PUSTAKA}

Ananta, P. W., \& Winiarti, S. (2013). MENGGUNAKAN METODE GAP KOMPETENSI. Jurnal Sarjana Teknik Informatika, 1, No.2, 574583.

Apridawati, F. (2015). SISTEM PENDUKUNG KEPUTUSAN PEMILIHAN SISWA BERPRESTASI PADA SD N I CAMPANG TIGA

Jurnal Ilmiah Fakultas Teknik "Technologia"
MENGGUNAKAN METODE AHP. STMIK Pringsewu Lampung.

Asfi, M., \& Sari, R. P. (2010). Sistem Penunjang Keputusan Seleksi Mahasiswa Berprestasi Menggunakan Metode AHP (Studi Kasus: STMIK CIC Cirebon). Jurnal Informatika, 6(2), 131-144.

Handojo, A., Setiabudi, D. H., \& Yunita, R. (2005). Pembuatan Aplikasi Sistem Pendukung Keputusan untuk Proses Kenaikan Jabatan dan Perencanaan Karir Pada PT.X.

Hasan, M. A. (2005). Sistem Pendukung Keputusan Penilaian Sertifikasi Guru Dengan Metode Gap / Profile Matching.

Sari, N. A., Widada, B., \& Susyanto, T. (2014). Sistem Pendukung Keputusan Pemilihan Mahasiswa Berprestasi Menggunakan Metode Analytical Hierarchy Process (AHP). Jurnal TIKomSiN, (ISSN : 2338-4018).

Supriyana, I. (2010). Perencanaan Model Arsitektur Bisnis, Arsitektur Sistem Informasi dan Arsitektur Teknologi Dengan Menggunakan TOGAF : Studi Kasus Bakosurtanal. Jurnal Generic, 5(1), 1-9.

Susanto, A. R. (2012). Sistem Pendukung

Keputusan Pengadaan Buku

Perpustakaan Stikom Surabaya

Menggunakan Metode K-Means

Clustering. Sekolah Tinggi

Manajemen Informatika \& Teknik Komputer Surabaya.

Wagino (2015) PEMILIHAN MAHASISWA BERPRESTASI (MAWAPRES) TINGKAT

FAKULTAS PADA FAKULTAS TEKNOLOGI INFORMASI UNISKA TAHUN 2015. Retrieved May 2, 2015, from fti.uniskabjm.ac.id/pengumuman_detail.html 